\section{L'Actualité économique}

L'ACTUALITÉ ÉCONOMIQUE

\section{Index des auteurs d'articles et des titres} Trente-quatrième année, numéros 1 à 4

Volume 34, numéro 4, janvier-mars 1959

URI : https://id.erudit.org/iderudit/1001453ar

DOI : https://doi.org/10.7202/1001453ar

Aller au sommaire du numéro

Éditeur(s)

HEC Montréal

ISSN

0001-771X (imprimé)

1710-3991 (numérique)

Découvrir la revue

Citer ce document

(1959). Index des auteurs d'articles et des titres : trente-quatrième année, numéros 1 à 4. L'Actualité économique, 34(4), 741-742.

https://doi.org/10.7202/1001453ar d'utilisation que vous pouvez consulter en ligne.

https://apropos.erudit.org/fr/usagers/politique-dutilisation/ 


\title{
Index des auteurs d'articles et des titres
}

\author{
(Trente-quatrième année, numéros 1 à 4)
}

Angers, Frangois-Albert:

Le concept d'inflation et les confusions de la politique monétaire..... 5

La place de la science économique dans les sciences de l'homme..... 232

B́́DARd, RogrR-J.:

La formation du personnel administratif en Europe occidentale...... 618

Bonin, Bernard:

La participation canadienne au plan de Colombo.............. 400

Le Canada et le G.A.T.T.............................. 669

Brouillette, Benoit:

La production d'énergie électrique au Canada .............. 150

Les routes maritimes des exportations canadiennes de blé........ 571

Buron, Jean:

Les relations commerciales anglo-canadiennes. .............. 363

Delputr, Jzan:

Déclin de l'industrie des machines agricoles................ 679

Dionne, Yvon:

L'interprétation des états financiers en période d'inflation......... 106

Gardner, Gérard:

Quelques aspects de la mise en valeur du Grand-Nord

III-Les ressources minérales des Territoires du Nord-Ouest et leurs problèmes............................... 89

IV - Le développement du nord de la Colombie-Britannique...... 557

Garigue, Philippe:

Les changements sociaux et les valeurs culturelles. 


\section{L'ACTUALITE ECONOMIQUE}

Harvey, Pirrre: $\quad$ Page

Keynes et le problème de la centralisation des pouvoirs......... 183

Théorie des salaires et offre de travail . . . . . . . . . . . . . 484

Huor, J.A.:

L'autofinancement dans l'industrie papetière au Canada . . . . . . . . 68

Juder, Stanislas:

La construction navale au Canada . . . . . . . . . . . . .... 209

LAUPENBURGER, HENRY:

La déconcentration des grandes villes et le développement économique régional. . . . . . . . . . . . . . . . . . .

McGee, J.C.:

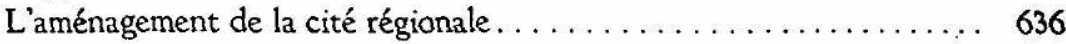

Mehling, Jean:

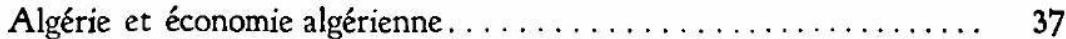

Notes sur l'évolution du système économique Yougoslave........ 436

Menace de grève et politique d'action sur les salaires . . . . . . . 470

Remarques sur le commerce franco-canadien et les importations canadiennes........................... 581

Parenteau, Roland:

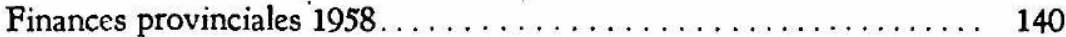

La Grande Dépression et ses répercussions régionales. . . . . . . . 523

Le financement des commissions scolaires. . . . . . . . . . . 660

Parizeau, Jacques:

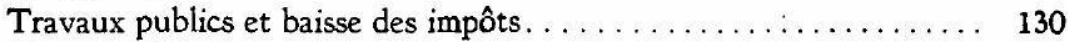

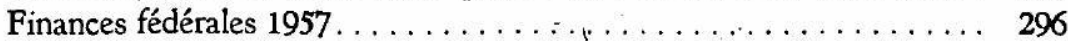

Hausse des prix et récession. $\ldots \ldots \ldots \ldots \ldots \ldots \ldots \ldots \ldots . \ldots \ldots$

Le commerce du Canada avec le Commonwealth . . . . . . . . . . . 383

L'automatisation et l'industrie manufacturière canadienne. . . . . . . 462

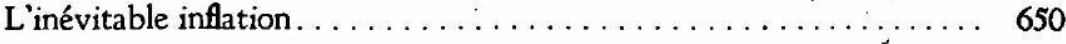

Poznanzki, ThaddéE:

Quelques remarques au sujet des taux de mortalité dans la province de Québec................................ 244

Rouquet la Garrigue, Victor:

Les banques fédérales de réserve et les modalités du crédit américain. . 274

Verhulst, Michel:

Influence du système de planification sur le niveau des stocks dans une entreprise de produits céramiques. 